Romanization of Korean and Japanese words and names follows the McCuneReischauer and the Hepburn systems, respectively. I have made exceptions in the case of historical figures, place-names, or newspapers when alternative spellings in the English language are well known (e.g., Park Chung Hee, Chun Tae-il, Kim Jin-Sook, Pyongyang, Seoul, Dong-A ilbo). In such cases the pertinent transliteration is provided in parentheses following the first occurrence of the word. Korean and Japanese names of authors who publish primarily in their native language are ordered according to the East Asian convention of providing the given name following the surname (e.g., O Kiyŏng). All translation is my own unless otherwise noted. 



\section{WOMEN IN THE SKY}

